\title{
MANAGING DIALOGIC USE OF EXEMPLARS
}

\author{
David Carless* and Kennedy Kam Ho Chan
}

*Corresponding author. Email: dcarless@hku.hk

Faculty of Education, University of Hong Kong

The analysis of exemplars is a potentially powerful way of acquainting students with academic standards and supporting their capacities to make informed academic judgments. This paper investigates the role of dialogue in supporting students to develop their appreciation of the nature of quality work. The research derives from a project involving nine teachers in a Faculty of Education and uses data from a single case to analyze the dialogic use of exemplars. The findings illustrate how the teacher prioritized student talk and withheld his own evaluative judgments in the management of the discussion. A related dilemma lies in the balance between the student voice in constructing their views on the nature of quality and explicit teacher guidance. The main significance of the paper lies in its description of how exemplars dialogue can be orchestrated and a discussion of some of the main features of the dialogue.

Keywords: assessment for learning; exemplars; dialogue; tacit knowledge

\section{Introduction}

Unless students have a conception of what good work looks like, it is difficult for them to produce quality assignments. One of the most promising ways of developing student understanding of the nature of quality is through discussing exemplars of student work. By producing accounts of strengths, weaknesses and how the work could have been done better, 
students gain experience in making academic judgments and compare their perceptions with those of the teacher (Sadler, 2010). This development of student capacities to make judgments is a core element of assessment for learning in higher education (Sadler, 1989; Boud, 2000).

We define exemplars as carefully chosen samples of student work which are used to illustrate dimensions of quality and clarify assessment expectations. Although exemplars could also be constructed by teachers (Handley \& Williams, 2011; Blair et al., 2014), we believe that using student samples is both authentic and user-friendly. The exemplars are sometimes the same assignment which students are working on (e.g. Orsmond, Merry \& Reiling, 2002) or may be similar parallel tasks (Hendry, Armstrong \& Bromberger, 2012).

There seems, however, to be some lack of teacher appreciation of the value of exemplars in supporting the development of student evaluative judgments (Thomson, 2013). A particular concern discouraging teachers from using exemplars is that some students may interpret them as model answers to be imitated (Handley \& Williams, 2011). The sensitive handling of the teacher-led discussion phase may mitigate this challenge by encouraging students to take ownership of insights and highlighting that quality work can take different forms (To \& Carless, 2015). Congruent with this position, it has been suggested that the quality of the dialogue about the exemplars is a key factor in helping students understand how academic judgments are made (Hendry et al., 2012; Bloxham, 2013). Through this dialogue, characteristics of quality can be made visible to students and teachers can illuminate their tacit ways of interpreting criteria (Handley \& Williams, 2011).

This paper is drawn from a project in which nine colleagues in a Faculty of Education researched the dialogic use of exemplars. The premise underpinning the project was that the dialogue 
around the exemplars is crucial in advancing student understanding of goals and standards but relatively little is known about what good dialogue around exemplars looks like. The aim of this paper which investigates a striking case from the project is to examine the organization and key moves in the discussion phase of an exemplars session. Its significance lies in its analysis of how dialogue was managed and illustrates a key dilemma in the dialogue phase: the balance between student construction of notions of quality and explicit teacher guidance.

\section{Analyzing exemplars to support student understanding of quality}

There is a modest and steadily developing literature on the use of exemplars as an element of assessment for learning in higher education. We structure our review into rationale and benefits; modes of implementation; main challenges; and conclude with a brief summary.

\section{Rationale and benefits}

A theoretical rationale for exemplars use lies in the concept of tacit knowledge (Polanyi, 1958), the kind of knowledge which is difficult to transfer verbally or in writing. Acquiring tacit knowledge takes place through activities, such as observation, imitation, participation and dialogue (Bloxham \& Campbell, 2010). When students are able to develop tacit knowledge which corresponds broadly with that of the teacher, they are positioned to make sense of the teacher's judgment and its rationale (Sadler, 2010). Exemplars are particularly useful vehicles for the development of this tacit knowledge.

Tacit knowledge is experienced rather than defined (Sadler, 2002) so the concreteness of exemplars can make them more accessible than lists of criteria in the form of rubrics. Exemplars play a role in supporting students to apply and make sense of criteria (Bell, Mladenovic \& Price, 2013). Students' active engagement with criteria and exemplars helps them to internalize 
assessment task requirements (Nicol, 2010). Analyzing exemplars supports students in making sound academic judgments and has potential to aid performance on similar tasks (Smith et al., 2013).

There is plenty of evidence in the literature that students from a variety of disciplines are positive about being exposed to exemplars (e.g. Hendry et al., 2012; Lipnevich et al., 2014). This is not surprising because by clarifying expectations, the process of preparing assignments is simplified (Carless, 2015). Exemplars show different ways of approaching a task (Orsmond et al., 2002), reduce some of the anxiety which surrounds assessment (Yucel et al., 2014) and provide students with increased confidence to tackle a task (Hendry \& Anderson, 2013). Analyzing exemplars seems to support student learning and appears to be a high-leverage pedagogic strategy for a minimal investment of time and resources (Smith et al., 2013).

\section{Modes of implementation}

The relevant literature shows that there are a variety of different ways of implementing exemplars: optional workshops (Rust, Price \& O’Donovan, 2003); online resources with or without annotations (e.g. Handley \& Williams, 2011); and part of regular timetabled classes (e.g.

Hendry et al., 2012). Exemplars by themselves are insufficient: they need to be interpreted so that insights can be applied to a specific assessment task (Handley, den Outer \& Price, 2013). A study in which five Law teachers used exemplars in different ways illustrates alternative modes of implementation (Hendry et al., 2012). Based on short interviews with three of the teachers, all reported starting with peer discussion of the exemplars then teacher ' $A$ ' focused on a teacher-led discussion; teacher ' $B$ ' emphasized only the weaknesses of the exemplars; and teacher ' $C$ ' did not carry out any explanation or follow-up. The students in the class of teacher ' $\mathrm{A}$ ' performed 
significantly better on their assignment than students in the other classes, suggesting that a balanced, teacher-led discussion of exemplars is important (Hendry et al., 2012), although the study does not elaborate how this dialogue was organized or managed.

\section{Main challenges}

Probably the main teacher concern about using exemplars is that some students might wrongly interpret them as standard model answers to be copied or plagiarized (Handley \& Williams, 2011). One way of mitigating this challenge is for students to link their analysis to assessment criteria (Bell et al., 2013). Another way of reducing temptation for student copying is for there to be some variation between the exemplar and the actual task which students are about to tackle (Hendry et al., 2012). It is also important for students to be exposed to more than one exemplar so they can discern that quality can be expressed in different ways (Sadler, 2010).

A second challenge is that students often find it difficult to evaluate samples accurately until they are exposed to teacher thinking about the rationale for the grades awarded (Handley \& Williams, 2011). There is a danger, however, that if students become too dependent on teacher guidance, their learning strategies are reduced to 'chasing what the tutor wants' (Orsmond \& Merry, 2013, p. 748.). There seems to be some need for teachers to enhance their skills in facilitating and leading student discussion about exemplars (Hendry et al., 2012). Teachers might identify ways of developing a responsive, interactive style of managing discussion of exemplars which sensitively explains their own thinking about key features of exemplars and also stimulates students' own critical thinking (Hendry \& Anderson, 2013).

\section{Summary}


There is a persuasive academic rationale for using exemplars in that their skilful use develops student understanding of standards and rehearses important skills in making academic judgments. There are a variety of implementation strategies noted in the literature but a lack of clear consensus about what good use of exemplars involves. The main learning benefits from exemplars seem to arise from the teacher-led dialogue but prior exemplars literature provides limited insight into how the dialogue might be facilitated.

\section{Method}

The study is framed by the following question:

What are the main features of a specific exemplars dialogue and how is it orchestrated?

\section{Context}

The first author was principal investigator of the exemplars project and acted as critical friend for the research reported in this paper. The second author was the teacher-researcher and carried out the dialogic use of exemplars with a class of nine third-year undergraduate teacher education students of science specialism. The small class size follows from the limited need for science teachers in the Hong Kong school curriculum which is dominated by the subjects of Chinese, Mathematics and English. The small class seemed to offer a promising context for dialogic use of exemplars. A further facilitating factor was that this group of students had been taught by the teacher-researcher in the previous semester and trusting relationships had been established. University ethical guidelines were followed, including voluntary participation, freedom to withdraw and the use of pseudonyms to preserve anonymity. 
In relation to the selection of exemplars for discussion, two excellent samples were chosen on the basis of a twofold rationale. First, although mindful that exemplars could be used to show diversity of standards along a quality continuum, we decided to use excellent exemplars on the grounds that students might have more to learn from high quality work. The second feature is that the exemplars were analogous to, but not the same as, the final assignment task as recommended by Hendry et al., (2012): both were reflective essays but the content and focus were different. The students in our study were required to write a reflective essay about their evolving views of effective practical work based on their analysis of a lesson video showing practical work in science. The criteria for the reflective essay were based on the generic criteria for the programme and focused on five elements: content; logic and coherence; understanding of relevant literature; language; and presentation format. Students used these criteria during the classroom analysis of the exemplars but in their reading of exemplars before coming to class, they used their own pre-existing notions of what good writing should involve.

\section{Data collection}

The research methods were qualitative in nature in keeping with a study of classroom practice. The perceptions of students on the use of exemplars were collected through three methods. An open-ended survey identified students' perceptions of their involvement in different forms of dialogue about the exemplars. Two fully transcribed focus group interviews carried out by the critical friend elicited students' perceptions of key issues in the implementation of the exemplars class. Exit slips, brief written reflections on developing knowledge and understandings (Leigh, 2012), documented students' perceptions of their learning from the relevant activities. Data from the teacher was collected in three ways. First, the critical friend conducted a fully transcribed in- 
depth interview focused on the rationale, implementation and challenges of the exemplars class, including a detailed discussion of the teacher's views of the nature of a successful exemplars dialogue. Second the teacher-researcher compiled a reflective journal involving three entries of about 3,000 words each which included his preliminary analysis of the student data. Third, the exemplar class was observed live by the critical friend and the video recording was transcribed for further analysis. Table 1 summarizes the data collection.

Table 1. Major data sources

\begin{tabular}{|c|c|c|}
\hline & Data Source & Description \\
\hline \multirow{3}{*}{$\underset{\stackrel{0}{0}}{\stackrel{0}{0}}$} & Open-ended Survey & $\begin{array}{l}\text { Investigated student views of their experience of engaging in } \\
\text { dialogue about the exemplars. }\end{array}$ \\
\hline & $\begin{array}{l}\text { Focus Group } \\
\text { Interviews }\end{array}$ & $\begin{array}{l}\text { Probed student views about issues arising from the dialogue } \\
\text { about the exemplars. }\end{array}$ \\
\hline & Exit Slips & $\begin{array}{l}\text { Collected students' views about their learning experiences in the } \\
\text { exemplar class. }\end{array}$ \\
\hline \multirow{3}{*}{ 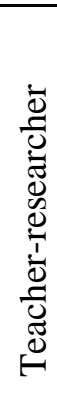 } & Teacher Interview & $\begin{array}{l}\text { Focused on issues in relation to the implementation of the } \\
\text { exemplar class. }\end{array}$ \\
\hline & Reflective Journal & $\begin{array}{l}\text { Analyzed the implementation of the exemplars class and the } \\
\text { student response. }\end{array}$ \\
\hline & Class Video Transcript & Enabled coding and analysis of the exemplars dialogues. \\
\hline
\end{tabular}

\section{Data analysis}

The video of the exemplars class was first transcribed verbatim and segmented with respect to the major classroom activities. Based on the transcript, the major activities related to the 
management of the exemplars dialogue were identified. To explore the exemplar dialogue further, the relevant parts of the teacher-led discussion were divided into idea units, denoting meaningful chunks of conversation (van Es, 2009). The coding scheme presented in table 2 was developed inductively from the data to describe how the teacher managed the exemplars discussion. We adapted some codes from existing schemes on teacher facilitation of discussions (Zhang, Lundeberg \& Eberhardt, 2011; van Es et al., 2014), whereas other codes, specific to exemplars, were original to our scheme e.g. codes 11-15.

Table 2. Coding scheme identifying teacher moves

\section{Codes Examples of teacher talk}

\begin{tabular}{|c|c|c|}
\hline$(1)$ & Eliciting student views & Any other view on that? \\
\hline (2) & $\begin{array}{l}\text { Eliciting views from a specific } \\
\text { student }\end{array}$ & Mario, anything to say? \\
\hline$(3)$ & Inviting questions from students & Any question you want to ask? \\
\hline$(4)$ & Probing for explanation & $\begin{array}{l}\text { I want to hear why classmates think that it is not appropriate to use a table in } \\
\text { the essay. }\end{array}$ \\
\hline$(5)$ & Re-voicing student views & $\begin{array}{l}\text { Winnie was saying that if we represent the ideas in a table format, then } \\
\text { probably it would limit the thinking. }\end{array}$ \\
\hline$(6)$ & Summarizing student views & $\begin{array}{l}\text { So you mentioned three points, one is that the author was able to identify the } \\
\text { change. }\end{array}$ \\
\hline$(7)$ & Elaborating student views & $\begin{array}{l}\text { It seems that this comment is pointing out something important. It is saying } \\
\text { that the structure of the paragraph is coherent and logical. }\end{array}$ \\
\hline$(8)$ & Praising contribution & Actually I think they raised a very good point. \\
\hline$(9)$ & Offering views & $\begin{array}{l}\text { In my view, the author knew a lot of theories. He understood the concepts but } \\
\text { he just didn't connect them purposively. }\end{array}$ \\
\hline$(10)$ & Wait time & Waiting for three to twenty-one seconds. \\
\hline (11) & Referring to the assessment criteria & So, sometimes we have to avoid the use of grand words because it may \\
\hline
\end{tabular}


illustrate to the assessor that you do not fully understand the words.

Remember the criterion of understanding relevant literature.

(12) Prompting reading of the exemplar

You may also refer to page 5 of the essay.

(13) Asking for an example

How about in Sample 2, what was the future action the author was

mentioning?

(14) Giving an example

I can read the relevant sentence from the exemplar: "These elements of good science teaching will form the blueprint for my future lesson planning”.

(15) Interpreting the exemplar

The author may be thinking that it is more important to motivate the students

to learn.

(16) Organisation

How about we start with the criteria of presentation format? Vicky and

Winnie, please share your work.

Other student and teacher data were uploaded to NVivo to facilitate data management. Our general approach was inductive analysis to generate understandings from the data. The teacherresearcher assigned codes to the data, building on the groundwork established through his reflective journal entries. Iterative cycles of further refinement followed from the challenges of the critical friend.

In order to enhance the trustworthiness of interpretations, we triangulated between different data sets and re-visited the data on multiple occasions during the writing process. As a further step, we invited the views of the other seven faculty team members in the exemplars project and used their comments to clarify our thinking. Faculty team members' views are selectively incorporated within the analysis.

\section{Limitations}


There are two main limitations to the study. The first relates to the small class and sample size which represents an unusual context and may limit the generalizability of findings. It is congruent with our aim, however, of illustrating the potential of dialogue around exemplars. The second limitation is common to most forms of teacher-research in that the personal involvement of the teacher-researcher may influence students' responses or lead to potential bias in the interpretation of data. These concerns were mitigated, to some extent, by the involvement of the critical friend in data collection and collaborative analysis. The larger group of faculty team members also enhanced our reflexivity by challenging our interpretations and raising alternative views.

\section{Findings}

We begin by describing the major activities to promote analysis of exemplars and the associated teacher rationale to provide a context for the later discussion of the dialogue. This is followed by discussing a number of classroom episodes. These episodes are chosen to illustrate the most salient features of the dialogue as identified by our coding scheme. In order to show the relationship between the codes and the findings, we indicate in parentheses the code from table 2 to which our analysis relates.

\section{Management and rationale of the exemplars class}

Analysis of the exemplars was organized in the following way. First, prior to the class students analyzed the strengths and weaknesses of the two exemplars and submitted their analysis to the teacher. Second, the teacher elaborated the rationale for analyzing exemplars. Third, students discussed their accounts of the strengths and weaknesses of the two exemplars in pairs. Fourth, students elicited views from classmates and summarized them in the form of mini-presentations. 
The third and fourth steps provided ample opportunities for students to share and discuss their opinions. Finally, students submitted an exit slip reflecting on their learning from the discussion of exemplars. Table 3 summarizes the major activities related to the exemplars, the various modes of student engagement and the time allocated.

Table 3. Major activities related to exemplars

\begin{tabular}{|c|c|c|c|}
\hline \multicolumn{3}{|c|}{ Major Activity } & \multirow{2}{*}{$\begin{array}{r}\begin{array}{c}\text { Engagement with } \\
\text { exemplars } \\
\text { Individual analysis }\end{array} \\
\end{array}$} \\
\hline Before class & \multicolumn{2}{|c|}{$\begin{array}{l}\text { ( Students analysed exemplars individually to identify } \\
\text { strengths and weaknesses. }\end{array}$} & \\
\hline \multirow{4}{*}{ During class } & Major Activity & Duration & \\
\hline & $\begin{array}{l}\text { 2Teacher explanation of the purposes of using } \\
\text { exemplars } \\
\qquad \Omega\end{array}$ & $10 \mathrm{mins}$ & \\
\hline & $\begin{array}{l}\text { 3Students working in pairs to share their } \\
\text { responses about the exemplars }\end{array}$ & 50 mins & Paired work \\
\hline & $\begin{array}{l}4 \text { Teacher-facilitated student mini- } \\
\text { presentations about the exemplars }\end{array}$ & 40 mins & $\begin{array}{l}\text { Whole class } \\
\text { analysis }\end{array}$ \\
\hline At end of class & \multicolumn{2}{|c|}{ (5 Student completion of exit slips to reflect on learning. } & $\begin{array}{l}\text { Individual } \\
\text { reflection }\end{array}$ \\
\hline
\end{tabular}

The teacher wrote about some of his intentions in his journal:

My rationale was to guide them to analyze the exemplars from individual, to peer, to teacherguided. I want to allow them to be exposed to divergent views about each dimension of the 
criteria and for them to have ample time to construct their own ideas. Through the peer talk, I want them to attend to some of the criteria that they wouldn't have noticed in their individual analysis. (Teacher journal entry)

When he was asked about the nature of a good exemplars dialogue, he responded as follows:

For a good dialogue, I think it should involve student ideas. The teacher should re-voice the student ideas so that finally it would be easier for the students to get the ideas about quality work. (Teacher interview)

In his reflective journal, he also mentioned not imposing his views on students:

I constantly remind myself that I should aim at a shared understanding instead of me didactically telling them. (Teacher journal entry)

His constructivist orientation seemed to be recognized by his students as in the following comment:

I think he tends to prefer not to do much teacher-telling. He actually didn't tell us how to structure a good reflection. Instead, he prefers to scaffold us to find out by ourselves how to write it. (Vicky, Focus group interview)

The management of the dialogue followed from this orientation of making students' views central. The coding of the video transcripts indicated that the most common facilitation move was eliciting student views (code 1). We highlight this aspect in the three episodes which follow. It is not our contention that the way of handling the dialogue is novel or special; it represents instead a baseline finding for what an exemplars dialogue might involve.

\section{Episode 1}


This episode arose from the student mini-presentation in relation to the criterion of presentation format and revolved around a student-identified issue of whether presenting information in tabular form is useful in a reflective essay.

\section{Transcript 1. Eliciting student views (code 1)}

1. Winnie: Actually there are mixed views of our classmates on this issue. The majority generally agreed that the ideas are well organized by the table but another group of students suggested that tables should be avoided in an essay. Is it really possible to have a table format?

2. Teacher: So the issue is whether we should have a table in an essay, some of you are saying that it's not appropriate. I want to hear why classmates think that it is not appropriate to use a table in the essay. Why do you think so?

3. Winnie: I think that the table format limits the ideas and creativity because the student has to refer to the heading of the column.

4. Teacher: Winnie was saying that if we represent the ideas in a table format, then probably it would limit the thinking. Is that what you mean?

5. Winnie: Yes.

6. Vicky: Or maybe tables are just for expressing some information and then you have some elaboration or discussion of the information in the table.

7. Teacher: So you mean that if the author is using a table, then there should be some related discussion?

The first teacher utterance summarized student views (code 6), probed for explanation (code 4) and elicited students' views (code 1). At turns 4 and 7, he re-voiced student views (code 5) but 
withheld his own judgment. Finally, he elicited opinions from the critical friend in transcript 2, following shortly after transcript 1.

Transcript 2. Offering views (code 9)

1. Critical We need to consider a piece of writing as an argument and if a table can help with our friend: argument then it is probably useful. I agree that either before or after it, there is usually some elaboration.

2. Teacher: So to sum up, the table is used to advance an argument and should be linked in some way to the text. It is reasonable to include tables in academic writing. So we can put tables but the next question I want you to think about is whether it is worth putting a table. This is another thing to consider.

Finally, the teacher offers his own view in the form of a summary which answers the student query about the acceptability of a table in an essay and adds that its potential value is the key consideration.

Students also stated their perceptions of this episode:

I realized there is freedom for us to build our essay. We can construct tables if we feel it makes things clearer, even though it depends on the requirements and content of the essay. (Betty, Exit slip)

We have effectively discussed the purpose, rationale and use of tables in an essay. It really contradicts my original view that a table should not appear in an essay. (Wallace, Exit slip)

These comments are suggestive of some development of student thinking or change of beliefs which are potentially worthwhile outcomes of the discussion. 
To summarize, this episode has illustrated some salient features of the exemplars dialogue. It addressed a question raised by students about the suitability of the use of a table in an essay. The discussion began with student views which were re-voiced and summarized, with the teacher withholding his own evaluative judgment until the very end of the episode. He wrote about this last aspect in his reflective journal:

Delaying judgment is important. I often learn a lot from my students how they think and I really want them to be aware of what their reasons are and to compare their views with others. (Teacher journal entry)

The delay of judgment seems important in allowing students the opportunity to reason together and revise their views in light of the discussion. An important implication for exemplars dialogue is the desirability of allowing students time and space to refine their evaluative judgments. This is something that many teachers may not feel inclined to do if they perceive other priorities, such as covering curriculum content.

\section{Episode 2}

The exemplar class afforded considerable time for peer-to-peer talk in line with the teacher rationale for students to construct their own views about the exemplars. This emphasis was generally supported by faculty team members who perceived that full student participation was an important part of an effective exemplars discussion. Students also seemed generally appreciative of the opportunities for them to construct their own ideas as illustrated by a number of representative comments:

Through discussion and interpretation, we really know the strength and weakness of our analysis and identify the criteria of a good reflective essay. (Open-ended survey response) 
Discussing with peers generated my thinking process and I could see more of what I didn't notice earlier. (Open-ended survey response)

Knowledge created by students themselves can leave a deeper impression than knowledge transmitted by spoon-feeding. (Linda, Exit slip)

In transcript 3 below, we show how the teacher used peer talk to bring out selected points from the exemplars. He observed two students having a useful discussion which he believed would benefit the whole class. He had noticed that under the criteria of content, the notion of consistent focus in an essay was not mentioned in the student mini-presentations. It occurred to him that he needed to solicit Linda's contribution to bring out this point. The following transcript shows how this intentional elicitation of student views was carried out:

Transcript 3. Eliciting views from a specific student (code 2)

1. Teacher: Any more things that you noticed? How about Linda? I heard that you talked to Tina and changed your views.

2. Linda: Yes, originally I thought that the author provided a lot of evidence to support his views but actually Tina mentioned the evidence is about the effectiveness of the teacher rather than evidence to support his view. So it is not too related to the task in the reflective essay.

3. Teacher: Linda was saying that originally she thought it is good for the author to provide evidence that the teaching is effective. But then on re-consideration, it seems to her that the main focus of the essay is about changing views of good science teaching rather than whether the lesson is effective or not. The evidence is not very focused on the changing views of science teaching. Is it what you mean?

4. Linda: Yes. 
5. Teacher: Sometimes when we're writing we lose a bit of our focus, so remember to think about the focus of your writing.

The teacher was able to capitalize on the peer discussion by eliciting from a specific student a dimension related to the exemplar. This strategy is contingent on his ability to listen attentively to the peer talk, something which would probably have been more difficult in a larger class. Linda expressed her own view in relation to this episode:

We can exchange our opinions and my views can be supported or supplemented by my peers. They also come up with some ideas that I didn't have. Analysing samples of student work is beneficial for cultivating critical thinking. When we judge others' work, it seems we can point out both strengths and weakness without bias. (Linda, Exit slip)

It seems that through the negotiation with her peers, Linda perceives that she is able to refine her thinking about the exemplars and develop wider skills in making unbiased judgments.

To sum up, this episode illustrates the potential value of peer discussion in the analysis of exemplars as students exchange ideas and reconsider previous positions. The teacher can elicit selected student views to build on student insights and make them visible to the whole class.

\section{Episode 3}

With time running out, the teacher concluded with a brief monologue which summarized a student contribution. Transcript 4 shows part of the concluding teacher discourse.

Transcript 4. Summarizing student views (code 6)

1. Teacher: I have actually selected some very good comments that you wrote in the preparatory 
task but we don't have sufficient time to cover them. So, for example, Tina is saying that sample 2 has a nice structure, introduction, development and wraps up the ideas at the end. I will post them on Moodle, have a look at them.

In accordance with his emphasis on the student voice, the teacher-researcher ended by summarizing a student view (code 6) and an organizational move (code 16) of inviting student follow-up on the Moodle platform. The critical friend questioned the teacher-researcher why there was a lack of summary about the exemplars at the end of the class. The teacher explained his thinking as follows:

The students may want me to elaborate the characteristics of a good reflective essay but that's not what I'm going to do. If they really think about the substance of the talk, I think they will get the key ideas. (Teacher interview)

He wanted students to develop their own concept of quality rather than being over-reliant on the teacher. When observing the class, the critical friend was convinced that there should have been a concluding summary aimed at sharing tacit knowledge and consolidating insights from the discussion of the exemplars. Subsequent data collection prompted the critical friend to reconsider this view and brought out some of the complexity of the issue. We present a representative selection of students' views below because they address key tensions in the balance between teacher and student voice:

Maybe sometimes if a teacher gives you too much guidance on what is expected, then you tend to follow his format. (Chris, Focus group interview)

It is appropriate for him not to conclude and let us find out something for ourselves. (Wallace, Focus group interview) 
We actually didn’t achieve much of a summary. Maybe it would be better if the teacher does that at the end. (Tina, Focus group interview)

Maybe he didn't want to tell us the answer directly but I think sometimes we need to be told what a good essay should be like. (Amy, Focus group interview)

These comments bring out some of the dilemmas between student co-construction of understandings and more explicit summaries of key points from the exemplars. The data showed that students were fairly evenly split between those who appreciated concluding in an openended way and those who wanted more explicit guidance. The majority view among faculty team members indicated that reaching some form of consensus through the discussion was an important part of an exemplars dialogue and a summary of that consensus would be an orthodox way of concluding.

To sum up this episode, we have discussed dilemmas in relation to appropriate ways of concluding the exemplars discussion. An advantage of an open-ended conclusion is that it encourages students to continue developing their own conception of quality. An advantage of a more explicit summary is that it might consolidate some key ideas from the discussion. Our supposition is that most teachers would conclude an exemplars discussion with some form of summary.

\section{Discussion}

This paper discusses an exemplars dialogue involving a small class; a motivated teacher enthusiastic about exemplar use; and the provision of extensive time for discussion. The dialogic use of exemplars was orchestrated through the following steps: 
1. Student pre-reading of exemplars prior to class to derive individual insights and preserve time for classroom dialogue;

2. Peer interaction to exchange views and apply assessment criteria;

3. Mini-presentations and teacher-orchestrated discussion in which ideas about quality writing are co-constructed;

4. Exit slips in which students consolidated reflections about the exemplars and enabled the teacher to understand their thinking.

Although relatively simple and user-friendly, we believe that these steps represent a modest enhancement on some of the modes of implementation used in previous literature. For example, in the study by Handley and Williams, (2011) online exposure to exemplars was arranged but there was limited student participation in online discussion. In the study by Hendry et al., (2012), only one of the teacher implementers reported leading a balanced teacher-led discussion of the exemplars, whereas the other two did not. No previous exemplars study has reported using exit slips which are an additional form of communication between the students and the teacher. A further element of exit slips, or alternative follow-up activities, could involve students planning how insights from the exemplar analysis might inform their own assignment. This additional stage would bring together two key aspects of students' learning from exemplars: making judgments; and transferring insights to their own work.

Analysis of dialogue is under-explored in previous exemplars literature. Dialogic use of exemplars is consistent with the idea that tacit knowledge is hard to communicate and needs to be experienced through interaction. In our study, the teacher-researcher orchestrated dialogue about exemplars by emphasizing the elicitation of students' views, whilst generally withholding his own judgment until the student voice had been thoroughly aired. Our analysis of the 
classroom talk enables us to identify the main features of the exemplars dialogue. The processes of teacher-led dialogue:

- Prioritized elicitation of student views and aired divergent viewpoints (e.g. episode 1);

- Privileged student thinking and reasoning about the exemplars (e.g. episode 2);

- Showed linkages between peer talk and whole-class discussion (e.g. episodes 2 \& 3);

- Provided some evidence of development in student views (e.g. episodes 1 \& 2);

- Made explicit some key qualities of the exemplars (e.g. episode 2).

We infer that the essence of a productive exemplars dialogue is a discussion in which multiple viewpoints are explored to facilitate the co-construction of reasoned judgments about the exemplars. The interplay between student construction of ideas and explicit teacher guidance represents a pedagogic choice which invites further research: what are the key parameters of a judicious balance between teacher commentary and student expression of ideas in an exemplars dialogue?

In order to enable productive exemplars dialogues, the teacher needs pedagogic sensitivity. This includes preparation of key potential messages prior to the exemplars discussion; flexible responses to students' evolving thinking; and adroitness in making use of student views to build shared understandings about quality. The teacher also needs skills related to elicitation, including use of wait time, attentive listening and the use of non-evaluative discourse. A faculty team member also added a useful point that discussion needs to go beyond surface features of exemplars and indicate how they relate to wider intended learning outcomes. Dialogue around exemplars should bring to the fore important features of quality rather than superficial strengths or weaknesses of the task response. 
A further contribution lies in this paper being possibly the first related to assessment for learning in higher education which has analyzed transcripts of exemplars dialogue. The coding scheme for analyzing how the teacher manages the exemplars dialogue (table 2) carries potential both to inform practice and act as a tool for further research. For example, the coding scheme could be used by teachers to reflect on the strengths and weaknesses of how they manage an exemplars dialogue. Further research could also uncover similar, different or additional teacher moves, including quantitative analysis of which moves are most frequent and qualitative investigation of the perceived value of the specific teacher facilitation strategies.

\section{Conclusion}

A central thesis of our paper is that the dialogic use of exemplars should be a core aspect of teachers' repertoire of assessment for learning strategies in that the development of student skills in making academic judgments is fundamental to the university experience. The potential benefits of using exemplars are enhanced by peer dialogue, providing students with opportunities to explain and reconsider their judgments. Subsequent teacher-led dialogue around the exemplars provides opportunities for teachers' tacit knowledge about standards and criteria to be acquired by students.

A critical issue is the wider applicability of the dialogic use of exemplars. How the dialogue might be managed in different disciplines or in varied contextual circumstances permits a considerable amount of flexibility across a number of dimensions. These include: the balance between oral and written dialogue about the exemplars; the extent to which online discussion of exemplars should be encouraged or required; the nature and extent of peer talk; how the teacher- 
led dialogue is managed; the extent and type of follow-up after the discussion; and the amount of time allocated to these possible activities.

A novel aspect of this paper is its analysis of the classroom dialogue in relation to exemplars. This also opens up various areas for further research. To what extent would a productive dialogue be harder to achieve with a larger class or different classroom dynamics? How might online dialogue about exemplars be effectively facilitated and monitored? What does a productive peer interaction about exemplars look like?

\section{Funding}

This research was supported by a Teaching Development Grant from the University of Hong Kong.

\section{Disclosure statement}

No potential conflict of interest was reported by the authors.

\section{References}

Bell, A., R. Mladenovic, and M. Price. 2013. "Students' Perceptions of the Usefulness of Marking Guides, Grade Descriptors and Annotated Exemplars." Assessment \& Evaluation in Higher Education 38 (7): 769-788.

Blair, A., A. Wyburn-Powell, M. Goodwin, and S. Shields. 2014. "Can Dialogue Help to Improve Feedback on Examinations.” Studies in Higher Education 39 (6): 1039-1054.

Bloxham, S. 2013. "Building 'Standards' Frameworks: The role of Guidance and Feedback in Supporting the Achievement of Learners." In Reconceptualising Feedback in Higher Education: Developing Dialogue with Students, edited by S. Merry, M. Price, D. Carless and M. Taras, 64-74. London: Routledge. 
Bloxham, S. and Campbell. L. 2010. “Generating Dialogue in Assessment Feedback: Exploring the use of Interactive Cover Sheets." Assessment \& Evaluation in Higher Education 35 (3): 291-300.

Boud, D. 2000. "Sustainable Assessment: Rethinking Assessment for the Learning Society." Studies in Continuing Education 22 (2): 151-167.

Carless, D. 2015. Excellence in University Assessment: Learning from Award-winning Practice. London: Routledge.

Handley, K., B. den Outer, and M. Price. 2013. "Learning to Mark: Exemplars, Dialogue and Participation in Assessment Communities.” Higher Education Research and Development 32 (6): 888-900.

Handley, K., and L. Williams. 2011. "From Copying to Learning: Using Exemplars to Engage Students with Assessment Criteria and Feedback." Assessment \& Evaluation in Higher Education 36 (1): 95-108.

Hendry, G., and J. Anderson. 2013. "Helping Students Understand the Standards of Work Expected in an Essay: Using Exemplars in Mathematics Pre-Service Education Classes." Assessment \& Evaluation in Higher Education 38 (6): 754-768.

Hendry, G., S. Armstrong, and N. Bromberger. 2012. "Implementing Standards-Based Assessment Effectively: Incorporating Discussion of Exemplars into Classroom Teaching." Assessment \& Evaluation in Higher Education 37 (2): 149-161.

Leigh, S. 2012. "The classroom is alive with the sound of thinking: The power of the exit slip." International Journal of Teaching and Learning in Higher Education 24 (2): 189-196. 
Lipnevich, A., L. McCallen, K. Miles, and J. Smith. 2014. "Mind the Gap! Students' Use of Exemplars and Detailed Rubrics as Formative Assessment." Instructional Science 42: 539559.

Nicol, D. 2010. "From Monologue to Dialogue: Improving Written Feedback Processes in Mass Higher Education.” Assessment \& Evaluation in Higher Education 35 (5): 501-517.

Orsmond, P., S. Merry, and K. Reiling. 2002. "The Use of Exemplars and Formative Feedback When Using Student Derived Marking Criteria in Peer and Self-Assessment.” Assessment \& Evaluation in Higher Education 27 (4): 309-323.

Orsmond, P., and S. Merry. 2013. "The Importance of Self-Assessment in Students' Use of Tutors' Feedback: A Qualitative Study of High and Non-High Achieving Biology Undergraduates." Assessment \& Evaluation in Higher Education 38 (6): 737-753.

Polanyi, M. 1958. Personal Knowledge: Towards a Post-critical Philosophy. London: Routledge and Kegan.

Rust, C., M. Price, and B. O'Donovan. 2003. 'Improving Students' Learning by Developing Their Understanding of Assessment Criteria and Processes." Assessment \& Evaluation in Higher Education 28 (2): 147-164.

Sadler, D. R. 1989. "Formative Assessment and the Design of Instructional Systems." Instructional Science 18 (2): 119-144.

Sadler, D. R. 2002. “Ah! ... So That's Quality.” In Assessment Case Studies, Experience and Practice from Higher Education, edited by P. Schwartz and G. Webb, 130-136. London: Kogan Page. 
Sadler, D. R. 2010. "Beyond Feedback: Developing Student Capability in Complex Appraisal." Assessment \& Evaluation in Higher Education 35 (5): 535-550.

Smith, C., K. Worsfold, L. Davies, R. Fisher, and R. McPhail. 2013. “Assessment Literacy and Student Learning: The Case for Explicitly Developing Students' 'Assessment Literacy'." Assessment \& Evaluation in Higher Education 38 (1): 44-60.

Thomson, R. 2013. "Implementation of Criteria and Standards-Based Assessment: An Analysis of First-Year Learning Guides.” Higher Education Research and Development 32 (2): 272286.

To, J. and Carless, D. 2015. "Making productive use of exemplars: Peer discussion and teacher guidance for positive transfer of strategies." Journal of Further and Higher Education, doi: 10.1080/0309877X.2015.1014317

van Es, E. 2009. "Participants' Roles in the Context of a Video Club." Journal of the Learning Sciences 18 (1): 100-137.

van Es, E., J. Tunney, L. Goldsmith, and N. Seago. 2014. "A Framework for the Facilitation of Teachers’ Analysis of Video." Journal of Teacher Education 65 (4): 340-356.

Yucel, R., F. Bird, J. Young, and T. Blanksby. 2014. "The Road to Self-Assessment: Exemplar Marking Before Peer Review Develops First Year Students' Capacity to Judge the Quality of a Scientific Report.” Assessment \& Evaluation in Higher Education 39 (8): 971-986. 
Zhang, M., M. Lundeberg, and J. Eberhardt. 2011. "Strategic Facilitation of Problem-Based Discussion for Teacher Professional Development." Journal of the Learning Sciences 20 (3): 342-394. 